\title{
Design Comparison of Creative Tang Suit and European Imperial Costume
}

\author{
Lin Lin \\ Tianjin Arts and Crafts Professional College \\ Tianjin, China 300250
}

\begin{abstract}
In China, people wear mainly two types of cloths: Chinese and western costumes. They are entirely different in styles, structures, materials, crats, dressing ideas and objects, etc. As plane-type clothing, Chinese traditional costume is highly decorative and naturally loose. As stereo-type clothing, western costume pays more attention to dress effect and excels at highlighting graceful human body. It possesses and reflects the spirit of the times. Chinese and western costumes have respective historical origins. Their appearances and evolutions are influenced by the life conditions and styles, cultural traditions, geographic environments and dressing ideas, etc.
\end{abstract}

Keywords-creative tang suit; creative european imperial costume; design

\section{INTRODUCTION}

In the process of its formation and progress, every nation in the world has formed a national traditional style with strong distinctive characteristics because of beliefs and aesthetic differences as well as some other complex reasons of living habits, natural environment, living conditions etc. This style is more prominent in art. An excellent design can best reflect the features of its national tradition and embrace a strong personality different from other nationalities in terms of the spirit and form. Chinese and Western clothing also show this kind of characteristic. Creative costume design with national style as its orientation often shines brilliantly on the international stage and good design works will leave a deep impression on people. With the clothing as a mirror, in today's diversified creative modeling style, more and more attention has been paid to the exploration and development of various ethnic clothing cultures.

\section{Features of Tang Suit and Creative Tang Suit}

Tang Suit is the best representative of Chinese costume. From Sui to Tang Dynasty, Chinese classical costume developed to its peak. In that period, political stability, developed economy, great progress in production and textile technology and frequent external exchanges prosper the clothing unprecedentedly. Then, new clothes styles, colors and patterns appeared. Chinese people, inclusive to others cultures during broad communication with other nations and countries, integrated other styles into their own clothes. Thus, many novel costumes were created. Colorful costumes of different styles flourished in Tang Dynasty. For example, the skirts of Tang Dynasty are superior to those of previous dynasties in materials, colors and patterns.

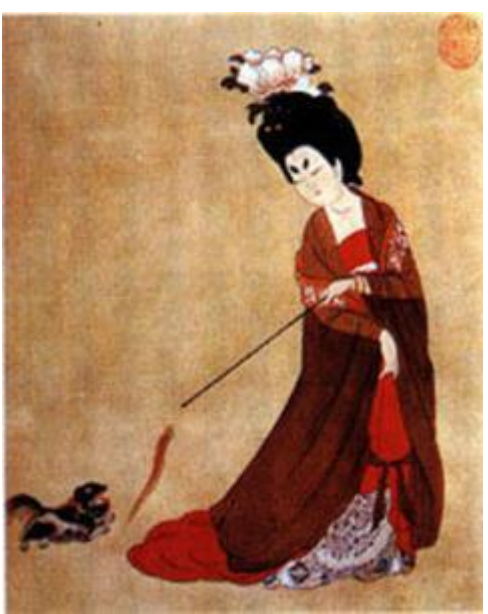

Fig. 1. Tang suit

In early Tang Dynasty, people wore high-waisted skirts and long scarves on the shoulders. There were two kinds of clothes: with front-opening and right-overlapping crossed collars. In flourishing Tang, narrow sleeves were replaced by full sleeves. In late Tang, Uighur clothes mainly in warm colors, prevailed. Red was preferred. Women wore clothes with wide hems on the collars and sleeves, toe-spring soft shoes, tube-tops inside, embroidered shawls outside, long tapering skirts and belts on the waist. It is a style very chic and unique, as shown in "Fig. 1".

The costumes in Tang Dynasty inherited the styles in Wei and Jin Dynasties. They integrated the elaboration of the patterns in Zhou Dynasty, the relaxation in the Warring States Period, the liveliness in Han Dynasty and the grace in Wei and Jin Dynasties. Then, with luxury added, the clothes and their patterns developed to the climax in the history. The clothes in Tang Dynasty influence even the clothes nowadays. As the time flies, the clothes in Tang Dynasty are innovated with new ideas on the fashion.

Nowadays, the creative Tang suit and the clothes in Tang Dynasty are identical in structure. But the production method is simplified. Now, most hand embroidery is replaced in the creative Tang suit by some accessories, such as sequins, acrylic diamonds and appliques, etc. These accessories can achieve some beautiful visual effects not able to be realized 
by the hand embroidery. Moreover, the operation is simplified at the same time. As for the fabrics, the TangDynasty costumes are made mainly of silk. However, besides the silk, yarn is used more for the creative Tang suit for higher cost performance because the creative Tang suit is only used for photograph, photography and performances.

\section{FEATURES OF EUROPEAN IMPERIAL COSTUME AND CREATIVE EUROPEAN IMPERIAL COSTUME}

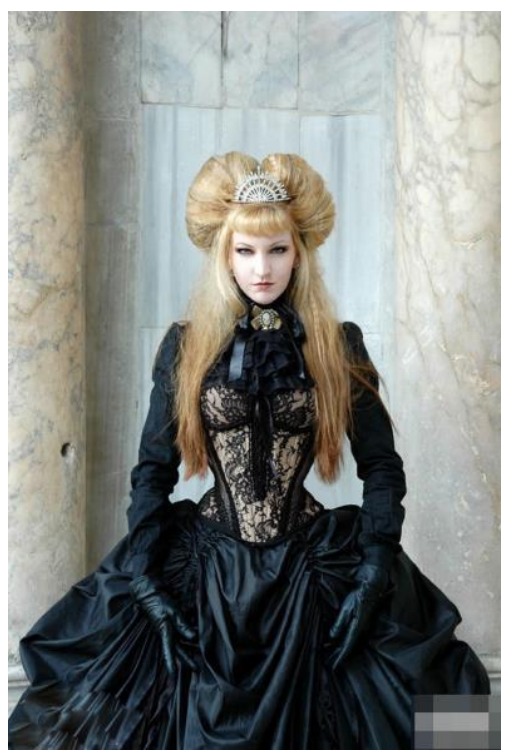

Fig. 2. Gothic suit.

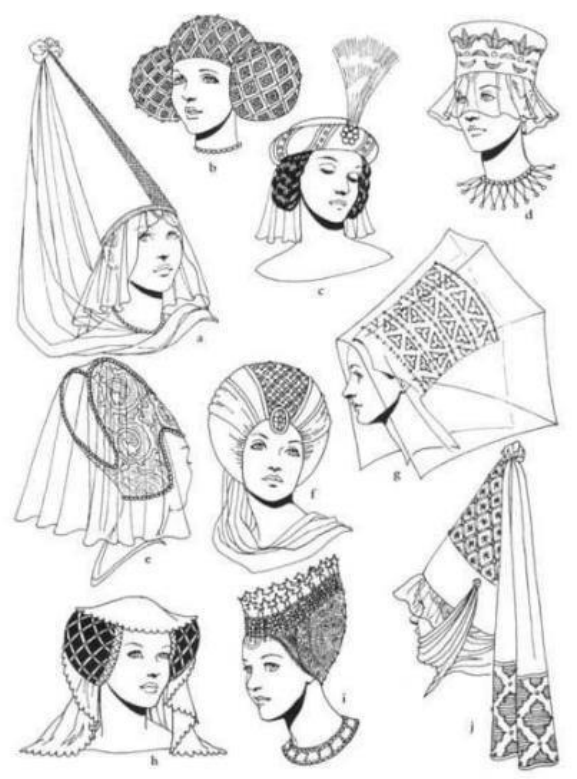

Fig. 3. Gothic headwear.

Occidental costumes evolved in styles. The wrapping style is in ancient Greece. The gothic style is the most popular between the 13th century and the 15th century in Europe. So, this period is called Gothic Age. The gothic style which integrates coldness, nobleness, romance, fetishism, mystery, darkness and depression expresses the gorgeousness in Victoria style in a way arrogantly cold, as shown in the "Fig. 2". Black and other dark colors are mainly adopted. The fabrics can be translucent but never exposing (thin nylon or netted fabrics). Leathers, PVC, rubbers and latex are all essential. Gothic clothes are influenced by gothic architectures largely. The features include vertical decorative and cutting lines. These vertical lines make the dresser look slender. The women's uppers are tight and the skirts are very loose, light in the upper part, heavier at the bottom and strongly decorative. Women wear silver accessories mainly but never golden accessories. The keynote of make-up is black and white: white foundation, black lipsticks, black eyeshadows, thin brows and black, bleached extremely light blond, red or purple hairs. As for accessories, T-shape cross (the sign of eternal life in ancient Egypt), five-pointed stars (the sign of fire, earth, air, water and soul for the heretics) and cross (the sign of the Christian) are usually adopted. There is a saying to describe the great charm of the Gothic that the Satan's lover is fascinated by the angels while the angels of the God love the Gothic.

A gorgeous head wear called escoffion was very popular in the 13th century, as shown in "Fig. 3". It parts the hair down from the middle. The metal wires, as a skeleton, form big hair balls of different shapes, such as cylinders, shells, etc. The hair balls are covered by hairnets, decorated by jewelries and finally covered by veils.

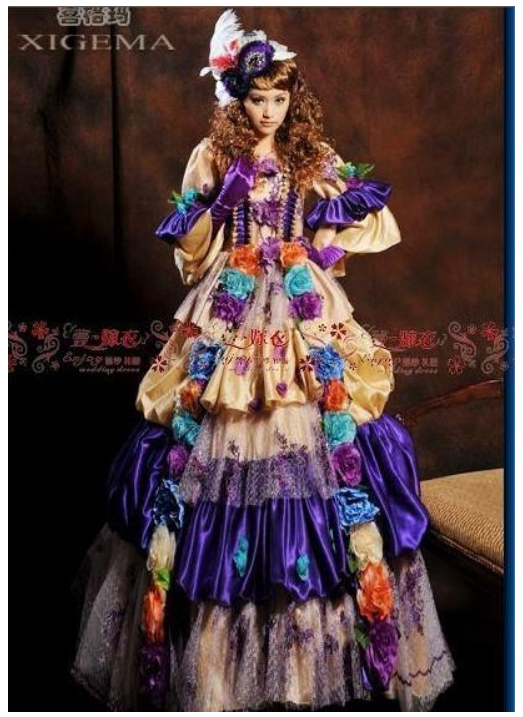

Fig. 4. Rococo-styled women's suit.

Since the $13^{\text {th }}$ century, figure clothes have become dominant gradually. Its basic forms are, for women, onepiece dress with silky edges, laces, velvet and light-colored dornicks. Rococo style is the most representative among the European clothes. The essential elements for Rococo clothes include exaggerated pannier, kilted laces, laborious decoration, low-cut underskirt and print cloth. As for the style design, classical " $X$ "-shape contour is usually used in the center to highlight the layering and quality of skirts and sleeves. In the usage of colors, rococo style gives up grey, black and white colors which is a little heavy and displays some showy colors on the fashion clothes, such as grass 
green, pink and light yellow, etc. Many flowers are painted on the fabrics of the Rococo-styled clothes. Moreover, many real or artificial flowers are used to decorate the clothes, as shown in "Fig. 4".

During the period of Louis $\mathrm{XV}$, rococo style reached the peak. The most typical feature of the dress is the pannier, bigger and bigger, in oval shape, flat in the front and at the back and wide at the two sides. It is said that the widest pannier reached four meters and even a double pannier appeared, as shown in the "Fig. 5". Rococo dress, very wide in hips, has very tight corsage. More or less, it makes the women those days more attracting and beautiful. The dress, very splendid, pays attention to extra decorations. Countless laces, ribbon knots, flower-shaped decorations and laborious folds are decorated all over the clothes. The collar band is widely opened in quadrangle. The sleeves extend to the elbows. Lis trimmings are decorated at the cuff. The dress becomes very bright and flowery. It achieves elegance delicate to the extreme, which means that women elaborate every detail of their clothes for men to appreciate. In that period, Madame de Pompadour wore mainly the clothes in this style, so these costumes are also called the style of Madame de Pompadour, which is the most magnificent representative for rococo dress, as shown in "Fig. 6". It was a sensual era when the most exquisite costumes for women are exposing and elegant. Thus, rococo period is a world where the women pursue magnificence. Rococo dress is often metaphorized into a magnificent flower basket full of flowers, laces, bowknots and ribbons.

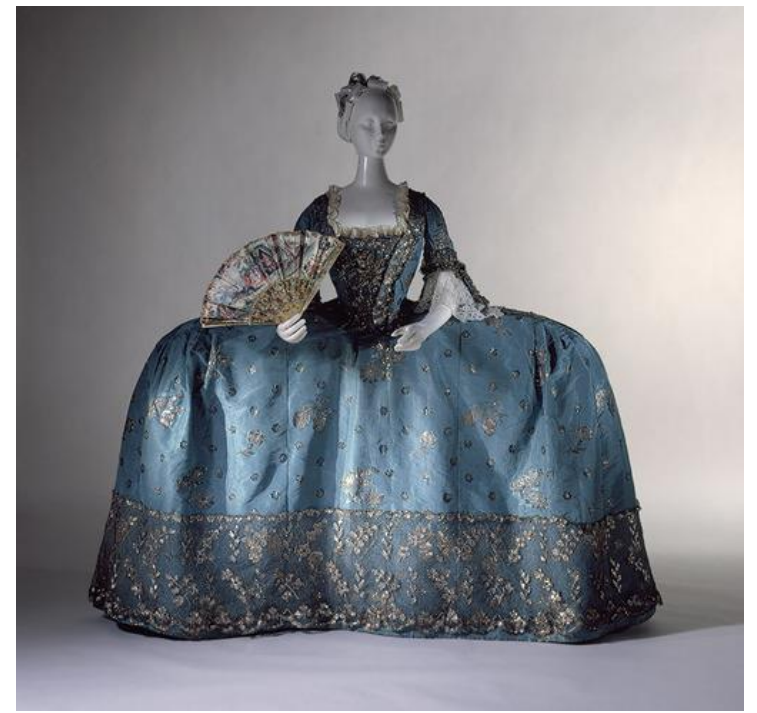

Fig. 5. Double pannier.

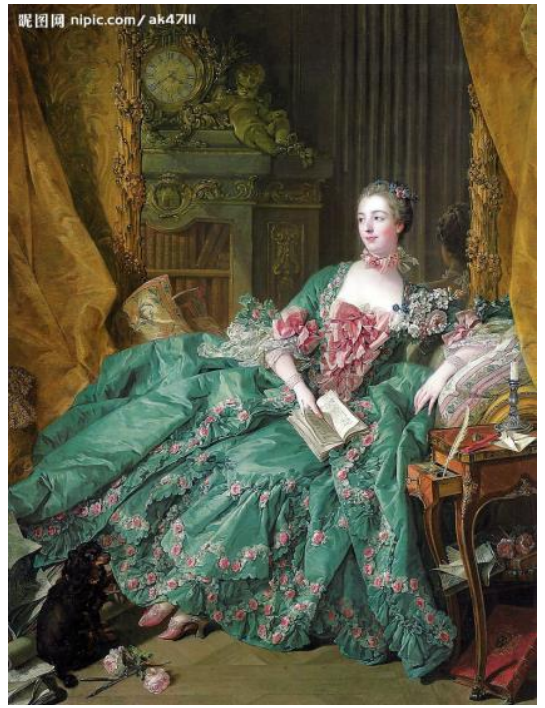

Fig. 6. Rococo-styled suit.

The new European imperial costumes add some modern elements and sense of fashion to the design as creativity on traditional European costumes. The creative European imperial costumes adopt also countless laces, ribbons, flowers, sequins, etc. As for fabrics, the woolen is replaced by the yarn. Accessories are various. Because they are mainly used for photography and performance, simpler production methods, environment-friendliness and better visual effects are the key points. During tailoring, slimming, enfolding, shoulder pads and belts are required. Full breasts and thin waist should be highlighted in the tailoring of women's costumes. No matter how fast the living tempo becomes, no matter how the styles are renovated, the design of the clothes is always manipulated by the westerners' wearing ideas and attention to the beauty of the body.

\section{THE COMPARISON BETWEEN THE CREATIVE TANG SUIT AND EUROPEAN COSTUMES}

We can find some differences, reviewing the development and current situation of Chinese and western costumes. On dressing, the Chinese pay more attention to the beautification of the appearance and self-adjustment. So, with less change, Chinese clothes are more conservative. The westerners advocate the beauty of the body and pays attention to the self-presentation. So, western clothes are opener and more innovative.

On the design idea, creative Tang suit, straight and loose, is plane full-slice style. There is no shoulder seam on the shoulder. The front and back cut-parts are linked. Even the sleeves are linked from the body. If the fabrics are not wide enough, the sleevelets can be added at the both sides of the sleeves. The creative European imperial costumes, closefitting and stereo, are in partitional style. Three-dimensional cutting is adopted. The horizontal visual effect is highlighted in the appearance. Thus, many accessories lateral-spreading are used, such as shoulder contours, various stiff collars, ruffs, inflated sleeves, large panniers, overlapped laces and flowers, starched yarns and pads on different body parts so that the costume lines can achieve an exaggerated and 
outward extending effects. Because the European costumes adopt set-in sleeves, not the linked sleeves, the shoulder pads and sleeves vary in styles and designs.

Some people think that creative Tang suit look like a plane drawing while creative European imperial costumes look like a stereo sculpture. That is because the Tang suit presents mainly two-dimensional effect and ignores lateral structure design. European costumes highlight threedimensional effect. They fit for the human body structure and motion law. They are both fit and practical. Thus, they are more popular and welcomed.

\section{DESIGNS OF CREATIVE TANG SUIT AND EUROPEAN IMPERIAL COSTUMES}

\section{A. Creative Tang Suit - "Oriental Garment”}

This work is, named as Oriental Garment, inspired by the lyrics in Melody of White Feathers Garment composed by Yang Yuhuan. Yang Yuhuan love wearing yellow skirt which is a symbol of higher status. Thus, orange and red are adopted in the overall design to present magnificence and nobleness. Orange slinky dress is worn inside. The skirt waist is put over the waist and tied by the ribbons, which makes the dressed look slender. Elbow sleeves, which develop from short jacket, cover outside. The half-arm long sleeves, which are also called half sleeves, and the symmetrical-pieces jacket, down to the waist, lace on the breast. The satin-faced printing patterns over the shoulders and twining between the arms are also called painting silks. They look extremely beautiful when they flutter during the walk. Round lapels and the swallow tail patterns on the shoulder indicate the temperament of a king. The beads in red and yellow check decorated on the brocade scarf, leather bands and the bottom of the collars indicate a sense of flow and rhythm. On the overall effect, the short upper garment and the floor-length skirt present the magnificence and grace of Tang suit, as shown in "Fig. 7".

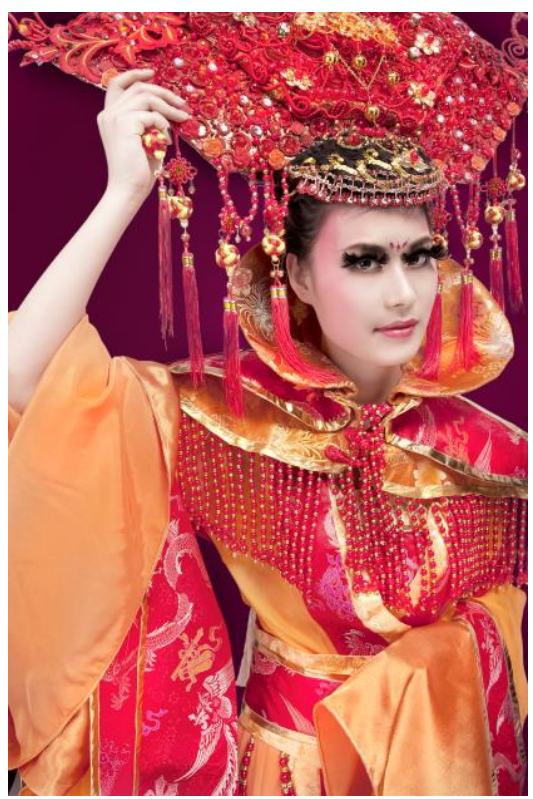

Fig. 7. Creative Tang suit.
The design of the red headwear is also very thoughtful. It is inspired by some Chinese elements: red rope of Chinse knot, red beads with Jingde blue printing, small lanterns in red and yellow check, peony and plume appliques and peony resins. The red ropes weave into clouding of different sizes and then some red crystal beads are pasted in the gaps to make the headwear dazzling and magnificent. Finally, the golden flower and golden arc accessories are pasted in the middle of the headwear to add a light spot to highlight the nobleness of oriental court.

As for the makeup and the eyeshadow, coper and golden in the same color system are used. Smoking and blooming are adopted around the eye holes to stretch the eye shape backwards. Exaggerated eyelashes are added to highlight the eye shape to present the charm and classical beauty. White transparent crystals pasted at the eye heads add some sense of spirituality. A golden flower is painted between the eyebrows, which is the unique feature of the makeup in Tang Dynasty. These are the soul of the whole makeup. Large area red blending is used as blushers, which corresponds with and harmonizes the whole makeup. Rose is chosen for the lips and golden color is spread on the high luster part to increase the sense of volume of the lips and to make the lips look very full.

\section{B. Creative European Imperial Costume - "Dark Night Flowing Pearl",}

"Dark Night Flowing Pearl" is inspired by the film Marie Antoinette. This film is a magnificent material feasting. All the clothes in the film are in rococo style. The costumes, light, delicate and elegant, pay much attention to laces, details and the mounted jewelries.

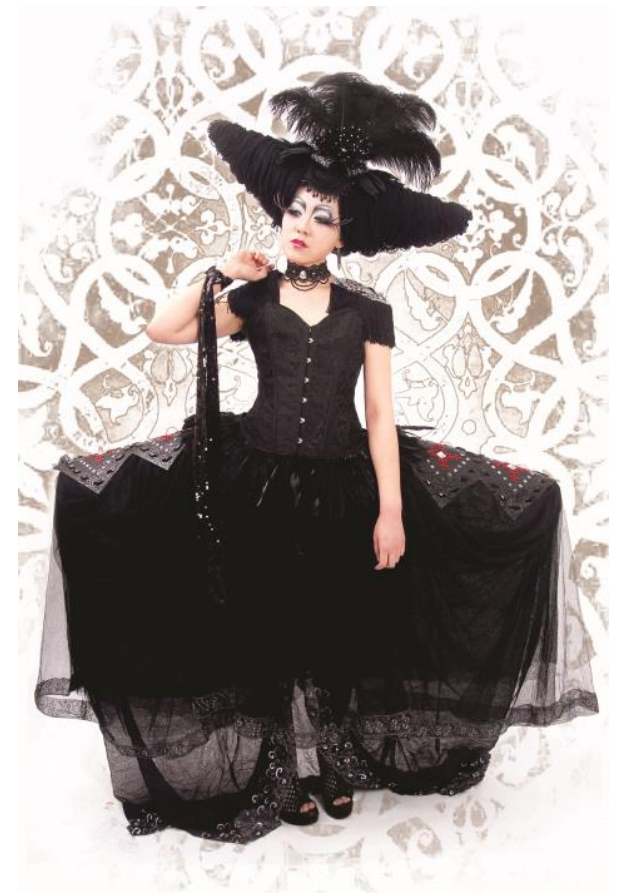

Fig. 8. European creative design. 
Based on rococo and gothic styles, the work creates an atmosphere of European court, as shown in "Fig. 8". The work is tight in the dress but loose in the skirts, the characteristics shared by the two styles. The corselet sets off the lines of the breast and the waist. Wide pannier and stacked gauzes exaggerate the lines of women's hips. Vshaped chest plate is used for the corselet, the main part of the upper part, to manifest women's body lines. Crossing ribbon laces at the back, jacquards and embroideries on the fabrics, countless ribbons and flower patterns are typical of rococo styles. The magnificent epaulettes decorated with fringes which are made of leathers and bright diamonds add some charms to the feminine gentleness. Wide pannier plat in the front and at the back is adopted to highlight the lines of the hip. The fabrics for hemlines are black gauzes. Four layers of gauzes in different lengths are stacked to create an atmosphere fantastic and mysterious. The most inner layer, which is also the longest, is in floor-length and decorated with embroidery lace of black or silver flower pattern. The gauzes of the outer layer build up some European imperial forms tiers upon tiers. The decoration made of leathers and bright diamonds on the upper part of the pannier corresponds with the epaulette. The gothic gauzes, the low-key element, are integrated with rococo element, such as ribbons, sequins, leathers, complicated folds, to present a high-key luxury in the mystery. The decoration of the clothes includes mainly the epaulette and the accessories at the upper part of the pannier. The epaulette takes the black printing as the background. Numerous acrylic gems mainly in silver, black and a few in red form some symmetric geometrical patterns. Black tassels are decorated by the side. The decoration on the pannier takes also the black leatherette printing as the background. The acrylic gems on the pannier form the geometrical designs which correspond with the epaulette. The designs on the shoulders and hips correspond with each other and add some fascination with the overall gentle style.

As for the accessories, black-laced chokers can highlight the feminine gentleness. Some black rosaries at the edge add some glittering for the matte laces. It adds some mystery on the gentleness. A big silver acrylic gem is put in the middle for a visual effect shining and luxurious. The eardrop is composed of a small, transparent and bright acrylic gem at the top and a tassel of numerous metal links at the bottom, very elegant and exquisite. There is no metal accessory on the hand, but a black cloth ribbon full of bright sequins stitched is tied on the wrist. These accessories make every movement of the dressed lively and mysterious.

The hair style is inspired by the gothic escoffion. Horizontally symmetrical, the hair style equilibrates with wide skirt hemline to avoid the top heaviness. Black is taken as the main color. The plastic and pressure-proof aluminum mesh constitutes a tower which extends along both sides. It is fixed on the base made of soft leathers. The gaps are also filled with aluminum meshes. Black threads are covered on the surface to replace hair pieces, as shown in "Fig. 9". Black is also the main color of the headwear. Black goose feathers with hard lines are wrapped layer by layer into a flower. Every petal is decorated with some small silver diamonds. Black goose feathers and rosaries are decorated on the edge.
The butterflies made of silver black jacquards, laces and embroideries are taken as the base. A black fan-shaped ostrich plume stands out from the back. The contract between the softness and hardness, the brightness and the darkness presents contrast of the colors and textures of rococo and gothic styles. However, the integration of these two styles is accidentally so beautiful.

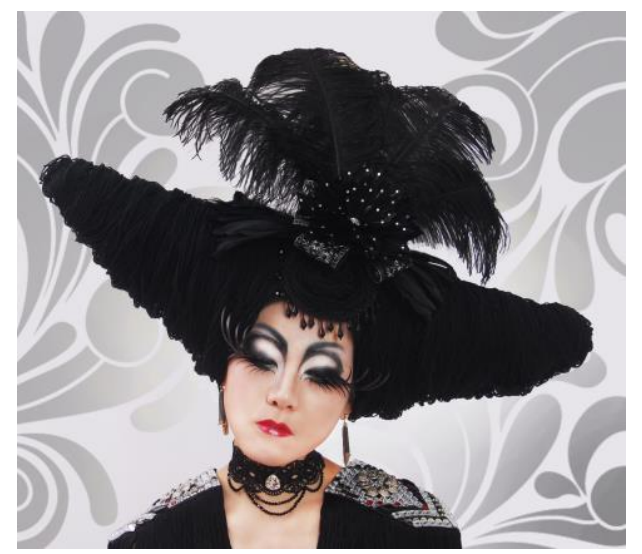

Fig. 9. European creative headwear.

The makeup is in gothic style with lifting eyebrows. The pale foundation takes black and white as main colors. Adding exaggerating eyebrows makes women more eyecatching. Silver and pearl colors and shining powders are added on the eyeshadows to make the eyes look bigger and more expressive. Bright red for the lips highlights the feminine fascination, different from gothic black. Because the five sense organs of the Europeans are more stereoscopic, for the shadows, the author pays more attention to the shadows beside the nose and draw deeper eyeholes. Moreover, the brightening of brow ridges, cheekbones, nose and jaw enhances the stereoscopic effect of the face. Matte carnation blusher, not so abrupt, can set off the coldness of the whole design.

\section{The Comparison of Creative Tang Suit and European Imperial Costumes}

Through comparison of the two works, we can conclude that the Tang suit "Oriental Garment" is reserved, gentle, magnificent and luxurious and that the European imperial costume "Dark Night Flowing Pearl", whose main color is black, is open, flamboyant, noble, luxurious and romantic. "Oriental Garment" presents the quality and status of oriental royal members while "Dark Night Flowing Pearl" presents the occidental elegance and female fascination. The Tang suit, in plane line cutting, displays two-dimensional effect. Delicate embroidery on the silk displays the oriental qualities. "Dark Night Flowing Pearl" in stereoscopic design displays three-dimensional effect. Various accessories on the clothes, such as stereoscopic laces, folds, plumes, acrylic gems and tassels achieve an intriguing effect and arouse a sense of beauty with their plentiful layers constituting spaces interspersed and overlapping. 


\section{CONCLUSION}

The differences between Chinese and western clothes lie on the different cultures. Chinese culture is a metaphorical culture. Its culture inclines to express emotions. Chinese people pursue that all the elements of the clothes have spiritual connotations and cultural tastes. The clothes, very wide, do not highlight the body curve and do not have sensory stimuli elements. They cover the body and present a solemn and reserved beauty. Western culture is a simile culture. The clothes pay attention to the objective beauty of the style, lines, designs and colors. It puts the visual comfort on the first place. Western culture advocates the beauty of human body and does not avoid presenting the sexiness. The modern fashion is to present the natural body shape in a way simple. Shortness, exposing and tightness are considered as the fashion. Chinese and western costumes cultures have respective rich connotations and distinctive characteristics. They are both precious cultural heritage from our ancestors. They are both the treasure in the world culture. We should continue to research and develop them based on the principle of criticalness.

\section{REFERENCES}

[1] Sun Yunfei. "Costumes in All Dynasties", Chemical Industry Press, Beijing, the 1st Printing, the 1st Edition in December, 2010.

[2] "Portrait Photography", the 8th Issue in 2008, No. 224.

[3] "The Influence of Four European Classical Styles on Dress Styles", "Gothic Style" \& "The Constitution of Gothic Costumes", Baidu Library

[4] Rococo Costume Culture, Douding Net. 